\title{
Levantamento fitogeográfico de Dalbergia L.f. (Leguminosae-papilionoideae) com potencial produtivo para própolis vermelha no Estado do Pará
}

\section{Phytogeographical survey of Dalbergia l.f. (Leguminosae-papilionoideae) with productive potential for red propolis in the state of Pará}

\author{
Raquel Leão Santos ${ }^{1}$; Daniel Santiago Pereira ${ }^{2}$; Sebastião Ribeiro Xavier Júnior ${ }^{3}$; Giorgio Cristino Venturieri ${ }^{4}$
}

\begin{abstract}
Resumo: O gênero Dalbergia L.f. (Leguminosae-Papilionoideae), de distribuição pantropical, compreende cerca de 250 espécies. Dalbergia spp tem sido amplamente explorada para produção de própolis vermelha, que consiste em uma mistura complexa feita pelas abelhas a partir do material resinoso encontrado no tecido meristemático em várias plantas deste gênero. Este trabalho tem por objetivo realizar levantamento da ocorrência da flora apícola produtora de exsudato vermelho que pode ser utilizada pelas abelhas africanizadas para produção da própolis vermelha no estado do Pará. Realizou-se o levantamento em diversos herbários que possuíam espécies de Dalbergia L.f. produtoras de exsudato vermelho no estado do Pará, juntamente com a sua distribuição. Para tanto, foram averiguadas literaturas específicas de morfologia e taxonomia que envolviam espécies de Dalbergia produtoras de exsudato vermelho localizadas no Pará. A coleta de dados foi obtida a partir da plataforma online SpeciesLink; e do acervo do Herbário IAN (Instituto Agronômico do Norte) da EMBRAPA Amazônia Oriental. O mapa de distribuição foi elaborado utilizando o software QGis juntamente com os dados de coleta das espécies. Foram encontrados 204 registros depositados em 21 herbários, sendo que, 175 são pertencentes à espécie Dalbergia monetaria e 29 à Dalbergia ecastaphyllum. Analisando os dados de coleta, notou-se que as espécies foram coletadas em 44 municípios do Estado do Pará, dos quais Belém e Bragança apresentaram maior quantidade de registros. A partir do levantamento realizado notou-se a predominância de Dalbergia monetaria nos registros, mostrando que esta é uma espécie que possui potencial para ser explorada.
\end{abstract}

Palavras-chave: Biodiversidade; Apicultura; Exsudato; Herbários

\begin{abstract}
The genus Dalbergia L.f. (Leguminosae-papilionoideae), with pan tropical distribution which comprises about 250 species. Dalbergia have been widely exploted for the production of red propolis, which consists of a complex mixture made by the bees from the red and balsamic resinous material found in the meristematic tissue in many plant species of this genus. The objective of this work is to survey the occurrence of the bee exuberant beehive flora that can be used by Africanized bees to produce red bee propolis in the state of Pará. Thus, the research aimed to carry out the survey in several herbaria that had species of Dalbergia L.f. producers of red exudate in the state of Pará, together with their distribution. Therefore, specific literatures on morphology and taxonomy were consulted involving Dalbergia species producers of red exudate located in Pará. The data collection was obtained from the online platform SpeciesLink; from the IAN (Instituto Agronômico do Norte) herbarium collection of EMBRAPA Amazônia Oriental. The distribution map was elaborated using the software QGIS together with collection data from the species. 204 records were found deposited in 21 herbariums, of which 175 belong to the species Dalbergia monetaria and 29 to Dalbergia ecastaphyllum. Analyzing the collection data, it was noticed that the species were collected in 44 municipalities of the state of Pará, in which Belém and Bragança presented more records. From the survey carried out, it was noticed the predominance of Dalbergia monetaria in the records, showing that it is a species that has potential to be explored; In addition, the work still promotes botanical studies and taxonomic revisions involving the target species of the present study.
\end{abstract}

Key words: Biodiversity; Beekeep;. Exudate; Herbarium

\footnotetext{
*Autor para correspondência

Recebido para publicação em 28/03/2017; aprovado em 14/06/2017

${ }^{1}$ Graduanda em Engenharia Florestal, Universidade do Estado do Pará, Belém. leaoraquel2014@ gmail.com.

${ }^{2}$ Doutor em Ciência Animal. Pesquisador em Apicultura Sustentável. EMBRAPA Amazônia Oriental. daniel.pereira@embrapa.br

${ }^{3}$ Especialista em Perícia e Avaliação de Impactos ambientais. Curador do Herbário IAN, EMBRAPA Amazônia Oriental. sebastiao.xavier@ embrapa.br

${ }^{4}$ Doutor em Ecologia. Pesquisador da EMBRAPA Amazônia Oriental.giorgio@ cpatu.embrapa.br
} 


\section{INTRODUÇÃO}

Dalbergia L.f., pertencente à família Leguminosaepapilionoideae, compreende cerca de 250 espécies de distribuição pantropical, sendo a sua ocorrência na América do sul centrada na Amazônia (LEWIS et al., 2005). Nos acervos dos herbários, podem ser encontrados exemplares deste gênero, possuindo grande importância para pesquisas na área de taxonomia e florística; além de serem utilizados para estudos comparativos, históricos e documentários da flora de uma região (BARBIERIL; LONGHI; SCIPIONI, 2007; MANIA; ASSIS, 2008).

Espécies desse gênero são cultivadas por diversas finalidades, como: Dalbergia spruceana Benth. para produção de madeira de boa qualidade (RIZZINI, 1990); Dalbergia nigra (Vell.) Allemão ex Benth por possuir madeira de alto valor econômico, é indicada na construção de mobiliário de luxo, para acabamentos internos na construção civil, além de ser uma espécie recomendada para recuperação de áreas degradadas, por depositar razoável camada de folhas e por mostrar grande amplitude de tolerância ambiental (CARVALHO, 2003); além de Dalbergia subcymosa Ducke que é utilizada pelo seu uso medicinal popular como tônico no tratamento de inflamações diversas (BERG, 2010).

Contudo, uma atividade que tem sido amplamente explorada a partir de espécies de Dalbergia é a produção de própolis vermelha; que consiste em uma mistura complexa feita pelas abelhas a partir do material resinoso vermelho e balsâmico dos ramos; flores; pólen; brotos e exsudados de árvores (BANKOVA et al., 2000). Sendo assim, A composição de uma própolis é determinada principalmente pelas características fitogeográficas existentes ao redor da colmeia (KUMAZAWA et al., 2004). Esta própolis foi inicialmente descrita na região de mangue do Estado de Alagoas tendo sua origem botânica identificada como Dalbergia ecastaphyllum (L.) Taub. (SILVA et al., 2008).

Entretanto, outra espécie do referido gênero também tem mostrado possuir potencial para produção de própolis vermelha, haja vista que Dalbergia monetaria L.f. foi descrita contendo exsudato resinoso vermelho (MIÑO et al., 1995).

Jain (2014) em seu estudo sobre origem botânica da própolis vermelha, através da comparação do material genético de amostras da própolis com o DNA de folhas de Dalbergia, concluiu que além de Dalbergia ecastaphyllum, que é tradicionalmente utilizada para produção dessa própolis, Dalbergia monetaria, também apresentou $100 \%$ de identidade com esta própolis; reforçando a indicação de seu uso na cadeia produtiva da própolis vermelha.

Alencar et al. (2007) observou que a própolis vermelha obtida da D. ecastaphyllum apresenta compostos biologicamente ativos nunca vistos em outras própolis. Neste mesmo estudo, a própolis vermelha apresentou atividade antioxidante, atividade citotóxica para células tumorais e atividade antimicrobiana.

Além das propriedades medicinais reconhecidas e utilizadas, principalmente pela indústria farmacêutica, a própolis vermelha possui uma agregação de valor diferenciada em relação à outras própolis. O preço dessa própolis oscila no mercado internacional entre US\$ 200 a US\$ 250 o quilo com produção insuficiente para atender a demanda. Atualmente os EUA são os principais compradores. A produtividade pode ser evidentemente aumentada pela adequação e uso correto de coletores, localização dos apiários, manejo, sazonalidade, flora disponível e sobretudo, pelo uso de rainhas geneticamente melhoradas (LIMA, 2005).

Somando aos fatores favoráveis para produção da própolis vermelha no estado do Pará, tem-se que a região norte detém um reconhecido potencial para o desenvolvimento das atividades de manejo com abelhas sociais, que é uma das grandes opções de exploração das potencialidades naturais da flora, representando, um excelente instrumento de geração de trabalho e renda para o homem do campo, podendo até remunerar melhor que as atividades agrícolas tradicionais (SILVA et al., 2006).

As atividades de manejo com abelhas sociais têm despertado grande interesse por parte dos agricultores, por não exigir muito tempo de dedicação, nem requer muita sofisticação em termos tecnológicos. Além disso, gera ocupação e renda para as famílias, incluindo jovens e mulheres (MARTINS et al., 2006). A sua exploração não requer altos volumes de investimentos iniciais nem grandes áreas de terra. Também não requer dos produtores rurais, técnicas especializadas e nem dedicação exclusiva (SOUZA, 2007).

Contudo, a falta de informações mais detalhadas sobre a própolis amazônica limita o interesse por parte dos produtores e compradores, já que em outros estados brasileiros este produto vem sendo profundamente estudado e caracterizado principalmente quanto à sua composição química e isolamento dos componentes para identificação dos elementos mais importantes nos efeitos promovidos pelo produto in natura. Além de que o estudo das espécies vegetais que fornecem esse exsudato vermelho ainda é incipiente, considerando o valor deste produto para a produção de própolis vermelha.

Apesar de que a biogeografia, sobretudo o ramo da fitogeografia, seja objeto de estudos há centenas de anos, uma observação feita por Hueck (1955) pode ser usada para retratar a situação atual: há uma escassez de levantamentos fitogeográficos detalhados abrangendo grandes regiões e que sirvam de embasamento para ações práticas de conservação e desenvolvimento sustentável.

Dessa forma, diante da importância dessas espécies para elaboração de própolis vermelha, o trabalho teve como o objetivo realizar o levantamento das espécies de Dalbergia L.f. produtoras de resina vermelha juntamente com a sua distribuição para o Estado do Pará.

\section{MATERIAL E MÉTODOS}

Para o desenvolvimento da pesquisa, foram averiguadas literaturas específicas de morfologia e taxonomia que envolviam espécies de Dalbergia produtoras de exsudato vermelho pertencentes ao estado do Pará.

A coleta de dados foi obtida a partir de três bases de dados principais: a plataforma online SpeciesLink produzida pelo Centro de Referência em Informação Ambiental (CRIA, 2017); o acervo do Herbário IAN da EMBRAPA Amazônia Oriental e do Herbário MG (Museu Paraense Emílio Goeldi), sendo os dois últimos manejados pelo sistema BRAHMS (Botanical Research And Herbarium Management System) (FILTER, 1996) e pelo software Specify (SAMBANDAN, ; CHOWDHERY, 2004), respectivamente. A partir destes, foram feitos os gráficos dos herbários consultados para realização do trabalho e dos municípios de coleta das espécies estudadas utilizando o programa Microsoft Office Excel 2007. 
Em seguida, realizou-se um levantamento das espécies de Dalbergia produtoras de exsudato vermelho nas três bases de dados, filtrando os registros de coleta para o Estado do Pará e, por município citado nas exsicatas. Além de consultar o site do IBGE para confirmação dos nomes dos municípios paraenses.

O mapa de distribuição foi produzido a partir do aplicativo Geographic Information System QGIS 2.18.0 (QGIS, 2017) utilizando as coordenadas geográficas originais de coleta dos registros encontrados, sendo que quando a localização original não estava disponível, foram utilizadas as coordenadas do município de coleta, juntamente com os shapefiles de vegetação e limites pertencentes ao Estado do Pará.

\section{RESULTADOS E DISCUSSÃO}

De acordo com o levantamento, observou-se 204 registros depositados em 21 herbários (Figura 1), nestes há a predominância de registros nos herbários do Museu Emílio Goeldi - MG e lnstituto Agronômico do Norte - IAN, os quais estão localizados no município de Belém (PA), sob a responsabilidade, respectivamente, do Museu Paraense Emilio Goeldi/CNPq e da Embrapa Amazônia Oriental. Esse resultado é explicado, pela valiosa documentação científica sobre a floresta amazônica, produto de mais de 100 anos de pesquisa botânica na região, fornecendo dados sobre características vegetativas e reprodutivas bem como, usos e áreas de ocorrência sobre os recursos genéticos vegetais da Amazônia (MARTINS-DA-SILVA et al., 1999).

Figura 1. Listagem das pesquisas aos Herbários e quantidade de consultas para coleta de dados de exsicatas com Dalbergia ecastaphyllum e D. monetaria no estado do Pará, Brasil.

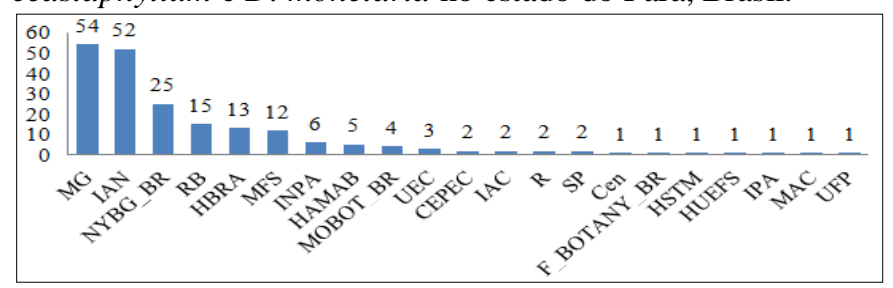

Do total de registros, 175 são pertencentes à espécie Dalbergia monetaria L.f. (Figura 2:A) e 29 à Dalbergia ecastaphyllum (L.) Taub. (Figura 2:B).

Lopez (2011) definiram a Própolis Vermelha do estado de Alagoas - PVA como o "produto oriundo de substâncias resinosas, gomosas e balsâmicas, colhidas pelas abelhas da espécie Apis mellifera, de brotos, flores e exsudados predominantemente da planta Dalbergia ecastophyllum (L) Taub. (Leguminosae, nome popular: Rabo de Bugio), de ocorrência na região litorânea e estuarino-lagunar do Estado de Alagoas, acrescidos das secreções salivares desses insetos, além de cera e pólen, para elaboração final do produto".

Além do que a composição da própolis é um reflexo da flora utilizada pelas abelhas, estudos demonstraram que a origem botânica da própolis vermelha é a espécie Dalbergia ecastaphyllum (JAIN et al., 2014).

Os poucos registros apresentados por $D$. ecastaphyllum ressalta a necessidade de mais coleta de material botânico a fim de amplificar os estudos com esta espécie, haja vista que esta apresenta inúmeras finalidades.

Apesar disso, vale destacar que Mendonça-Melo et. al (2017), após realizado Comparação de amplitude ribossômica encontraram que as espécies D. ecastaphyllum e $D$. monetaria da região do Rio São Francisco eram semelhantes genéticamente.

Figura 2. Exsicatas das espécies levantadas. A: Dalbergia monetaria L.f.; B: Dalbergia ecastaphyllum (L.) Taub, Belém Estado do Pará.
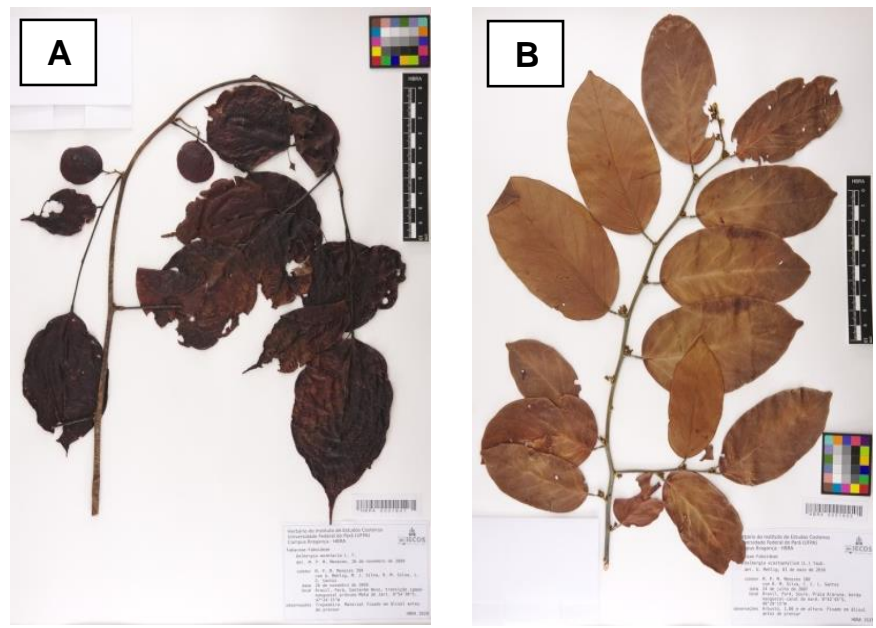

Fonte: Herbário do museu Emílio Goeldi e Herbário do Instituto Agronômico do Norte - Embrapa Amazônia Oriental (2017).

Segundo Mata et al. (2014), a área de ocorrência da D. ecastaphyllum (L.) Taub é muito vasta, e se estende desde o sul da Flórida (EUA) ao sul do Brasil, assim como na costa ocidental da África. No Brasil, tem como domínios fitogeográficos a Amazônia e a Mata Atlântica, em áreas influenciadas pelo mar, como manguezal e restinga (MATA, 2014).

No processo de levantamento dos municípios de coleta, notou-se que as espécies foram coletadas em 44 municípios do estado do Pará, dos quais Belém e Bragança apresentaram maior quantidade de registros; ademais 24 registros apresentaram-se sem informações quanto sua localidade, conforme verifica-se na Figura 3 e representados na figura 4.

Figura 3. Municípios de coleta de Dalbergia ecastaphyllum e D. monetaria do acervo dos herbários IAN, MG e da plataforma SpeciesLink.

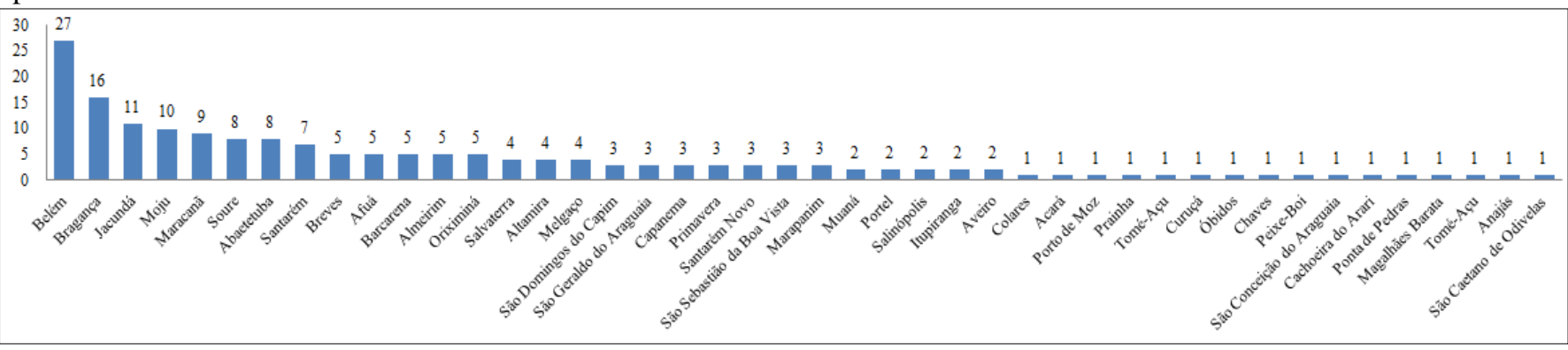

Revista Verde, v. 12, n. 3, p.590-595, 2017 
Figura 4: Levantamento fitogeográfico de ocorrência das espécies Dalbergia ecastaphyllum e D. monetaria encontrados em arquivos de herbários para o estado do Pará, Brasil.

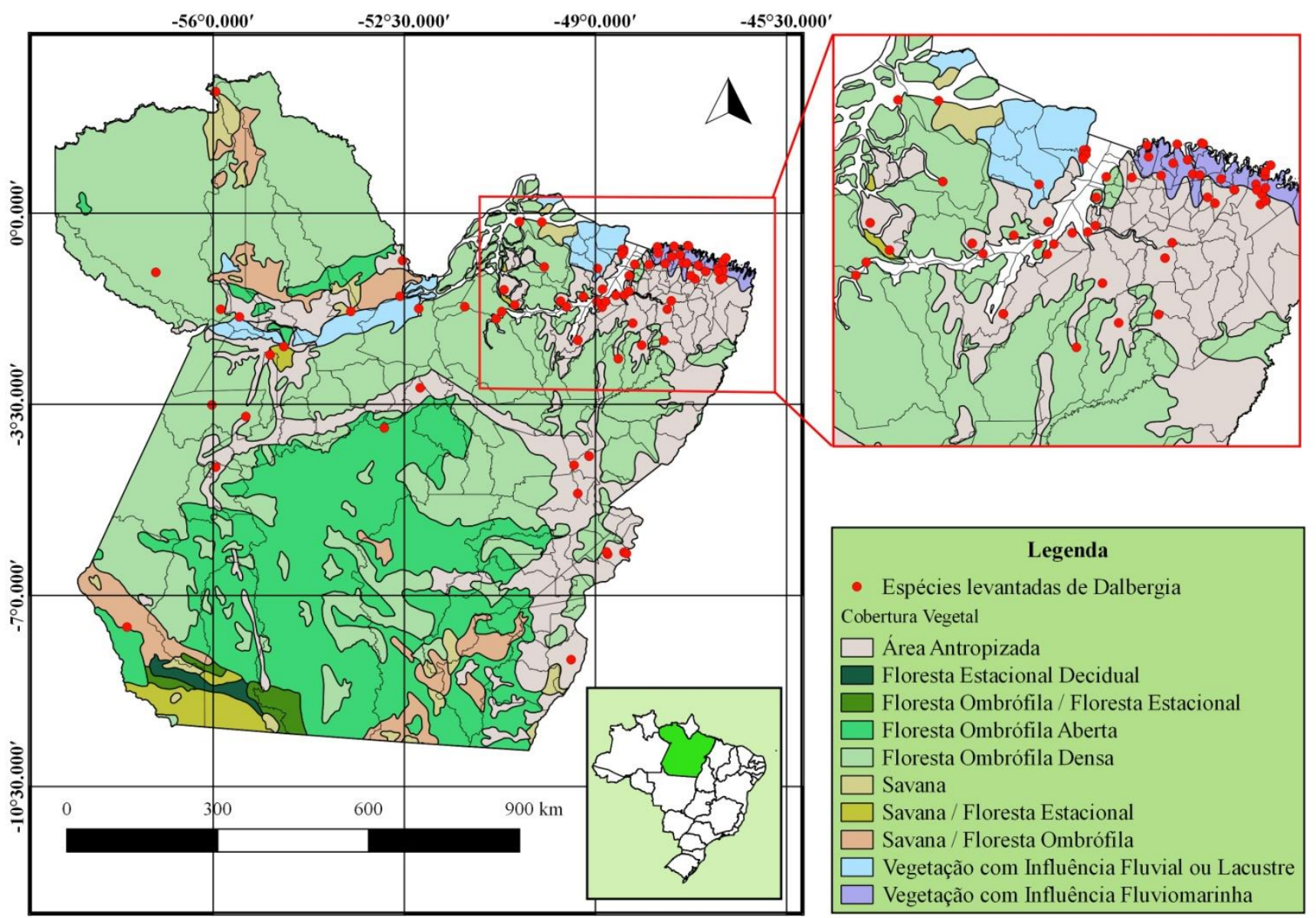

Fonte: Geographic Information System QGIS 2.18.0 (QGIS, 2017).

Dados compilados na Lista das Espécies da Flora do Brasil (FORZZA et al., 2010) demonstram que a região Amazônica, em relação a outras regiões do Brasil, é a que apresenta maior lacuna de conhecimento sobre a riqueza e diversidade taxonômica. O maior nível de conhecimento da flora Amazônica é visto próximo às capitais, como Belém, Macapá, Porto Velho e Boa Vista, e nos principais rios, como Amazonas, Tocantins, Tapajós, entre outros (HOPKINS, 2007)

Observa-se no mapa fitogeográfico a dominância das espécies em locais que a vegetação possui alguma influência fluviomarinha. Outras se concentraram em fragmentos de floresta ombrófila aberta próximos de áreas antropizadas. Conforme Carvalho (1997), a distribuição de Dalbergia ecastaphyllum (L.) Taub. está associada principalmente com estuários de rio, bancos de riachos, ou manguezais, onde seu hábito semi-prostrado e de caule múltiplo ajuda na estabilização da areia, sendo ainda encontrada menos frequentemente em vegetação seca de restinga ou em solos arenosos como um arbusto robusto ou uma árvore pequena. Enquanto Dalbergia monetaria L.f., no mesmo estudo, é descrita como abundante ao longo das margens periodicamente inundadas dos rios do estuário amazônico, onde forma uma massa emaranhada de caules e folhagens semelhantes aos do mangue.

Estas informações concordam com Aresi (2011), onde o autor afirma que existe uma predileção das espécies por ambiente, afirma que $D$. ecastaphyllum cresce em locais em que há constante vaporização de sal e em solos moderadamente salinos.

Contudo, a ausência de registros em outros tipos de vegetação do Estado não significa que não há ocorrência de espécies nesses locais, mas indica localidades que podem ser futuramente estudadas com o intuito de realizar novas coletas.

As informações aqui relacionadas já podem direcionar trabalhos para avaliar o potencial de diversificação de atividades e geração de renda no meio rural para a apicultura paraense, utilizando como recurso as indicações geográficas aproximadas nos locais de coleta das exsicatas listadas neste trabalho, poder-se-ão instalar colmeias nos locais para selecionar enxames de abelhas africanizadas adaptadas ao bioma amazônico com maior predisposição para coleta deste tipo de resina para acumular como própolis nas colmeias.

A partir do momento em que tenha sido constatado a visitação por abelhas do gênero Apis nas exsudações das espécies de Dalbergia nas condições ambientais do estado do Pará, as informações obtidas neste trabalho poderão ser utilizadas de modo a indicar os potenciais locais para instalações de apiários com base nos registros botânicos.

Além do que considerando que de acordo com Trusheva et al., (2011), os produtos oriundos das abelhas têm grande relevância no cenário mundial, muito disso se deve, ao fato destes apresentarem atividades biológicas, a própolis é produzida por abelhas e tem sido relatado na literatura como um agente promotor de atividades antibacterianas. 
Pereira et al., (2016), avaliando o efeito de inibição de desenvolvimento bacteriano usando 7 propolis do Rio Grande do Norte, encontraram que o Extrato Alcoólico da Própolis vermelha do mangue foi efetivo para Enterobacter aerogenes, Escherichia coli Salmonella spp., Staphylococcus aureus. Enquanto que os demais extratos de própolis apresentaram especificidade maior em uma ou duas bactécias.

Ademais, para que a apicultura seja viável diferentes estratégias podem ser adotadas como a diversificação dos produtos e a agregação de valor aos produtos da colmeia (POPOVICI; MĂRGHITAŞ, 2013; INGRAM; NJIKEU, 2011). Os empreendimentos apícolas eficientes combinam o desenvolvimento de um ou mais distintos sistemas de produção, como produção de abelhas rainha, favos de cera aveolada, colmeias, no intuito de usufruírem do máximo da lucratividade do apiário (POPOVICI et al., 2014).

Castilhos et al., (2016), indica que apicultores do Rio Grande do Norte exploram produtos diversos da colmeia, como os serviços de polinização, produção de enxames, produção de mel, pólen, própolis e apitoxina.

De acordo com Sampaio (2012), a própolis mostra-se rentável devido ao preço de comercialização superar o preço do quilo do mel, principalmente se exportada para países como o Japão e Ásia.

Levantamentos envolvendo novas indicações de espécies utilizadas para a produção de própolis vermelha são raros; Costa et al., (2013) realizou um levantamento dos estudos com a própolis na Bahia, porém sem indicar novas perspectivas.

No estado do Pará a produção de própolis é quase inexistente, isto é predominantemente devido à falta de conhecimento sobre as potencialidades das própolis e seu valor de mercado. Em vista disso, há uma necessidade urgente de estudos para explorar e identificar os gargalos produtivos da própolis apícola nas condições amazônicas. A identificação de plantas produtoras da própolis vermelha no estado do Pará poderá ser o primeiro passo para a inserção dos produtores do estado na cadeia produtiva da própolis. Apesar disso o Pará goza de uma enorme diversidade florística, bem como condições climáticas favoráveis com um período de floradas durante quase todo o segundo semestre do ano que podem enriquecer a diversidade de opções de própolis da Amazônia. Por outro lado, para expandir produção de própolis, os apicultores precisam de educação e treinamento sobre como coletar própolis com eficiência, juntamente com métodos de armazenamento e préprocessamento. Essa educação pode resultar em um fluxo de receita extra para apicultores e aumento da diversidade de produtos ofertados no mercado, gerando receita adicional para as famílias de produtores tradicionais envolvidos.

\section{CONCLUSÕES}

Há predominância de Dalbergia monetaria nos registros, mostrando que esta é uma espécie que pode apresentar potencial para ser explorada de forma sustentável para produção de própolis;

Constatou-se a existência de Dalbergia ecastaphyllum nas regiões de mangue no estado do Pará, demostrando o potencial para obtenção de própolis vermelha no estado do Pará;

Ficou evidenciado a oportunidade do estado do Pará ser inserido no contexto do mercado mundial para a cadeia produtiva da própolis vermelha podendo a diversificação da produção vir a se tornar uma ferramenta para geração de renda na pequena propriedade rural.

\section{AGRADECIMENTOS}

À Fundação Amazônia de Amparo a Estudos e Pesquisa do Pará (FAPESPA) pela bolsa concedida através do Programa Institucional de Bolsas de Iniciação Científica (PIBIC).

\section{REFERÊNCIAS}

ALENCAR, S. M.; OLDONI, T. L. C.; CASTRO, M. L.; CABRAL, I. S. R.; COSTA-NETO, C. M.; CURY, J. A.; ROSALEN, P. L.; IKEGAKI, M. Chemical composition and biological activity of a new type of Brazilian propolis: red propolis. Journal of Ethnopharmacology, v.113, n.2, p.278283, 2007.

BANKOVA V. S.; CASTRO S. L.; MARCUCCI, M. C. Propolis recent advances in chemistry and plant origin. Apidologie, v.31, n.1, p.3-15, 2000.

BARBIERIL, J.; LONGHI, J.; SCIPIONI, M. C. Sistema informatizado para manipulação eletrônica de dados de coleções científicas de plantas. Revista Brasileira de Biociências, Porto Alegre, v.5, n.2, p.783-785, 2007.

VAN DEN BERG, M. E. Plantas medicinais na Amazônia. Belém: Museu Paraense Emílio Goeldi.. 268p. 2010.

CASTILHOS, D.; BERGAMO, G. C.; FONSECA, V. L. I.; BELCHIOR FILHO, V. Apiculture in Rio Grande do Norte, Brazil: a four-year follow-up survey. Latin American Journal of Business Management v. 7, n. 1, p. 96-116, 2016, Taubaté, SP, Brasil. 2016.

CARVALHO, P. E. R. Espécies arbóreas brasileiras. Brasília, DF: Embrapa Informação Tecnologia; Colombo-PR: Embrapa Florestas, 1: 1039p. 2003.

CARVALHO, A. M. A synopsis of the genus Dalbergia (Fabaceae: Dalbergieae) in Brazil. Brittonia. The New York Botanical Garden, Bronx, NY. v.49, n.1, p.87-109. 1997.

CRIA. Centro de Referência em Informação Ambiental. Disponível em: <http://splink.cria.org.br/>. Acesso em: 02. fev. 2017.

COSTA, A. S.; MACHADO, B. A. S.; UMSZA-GUEZ, M. A.; PADILHA, F. F. Levantamento dos estudos com a própolis produzida no estado da Bahia. Sitientibus: Ciências Biológicas, v.13, p.1-7, 2013.

DEEPAK M. K. Propolis: A Neglected Product of Value in the Indian Beekeeping Sector, Bee World, 94:3, 80-83, 2017. DOI: 10.1080/0005772X.2017.1345223. 2017.

FILTER, D. L. Botanical Research And Herbarium Management System, BRAHMS, Version 4.0. University of Oxford, Oxford. 1996.

FORZZA, R. C.; BAUMGRATZ, J. F. A.; BICUDO, C. E.; CANHOS, D. A. L.; CARVALHO JR, A. A.; COSTA, A.; LUGHADHA, E. N. Síntese da diversidade brasileira. In: Forzza, R. C. et al. Catálogo de Plantas e Fungos do Brasil. Andrea Jakobsson Estúdio: Instituto de Pesquisas Jardim Botânico do Rio de Janeiro. 2010. v.1, p.21-42. 
HOPKINS, M. J. G. Modelling the known and Unknown plant biodiversity of the Amazon Basin. Journal of Biogeography. p.1400-1411. 2007.

HUECK, K. O mapeamento fitogeográfico e sua importância prática para silvicultura. Anuário Brasileiro de Economia Florestal. v.8, n.8, p.90-96. 1955.

INGRAM, V.; NJIKEU, J. Sweet, Sticky and Sustainable Social Business. Ecology \& Society. 16(1): 37. 2011.

JAIN, S.; MARCHIORO, G.; MENDONÇA, L.; BATISTA, M.; ARAÚJO, L. Botanical origin of the Brazilian Red Propolis: a new approach using DNA analysis. Journal of Apicultural Science, v.58, n.2, p.79-85, 2014.

KUMAZAWA, S.; HAMASAKA, T.; NAKAYAMA, T. Antioxidant activity of propolis of various geographic origins. Food Chemistry, v.84, n.3, p.329-339. 2004.

LEWIS, G.; SCHRIRE, B.; MACKINDER, B.; LOCK, M Legumes of the World. Richmond: Jardim Botânico Real. 2005. 592p.

LIMA, M. G. Efeito de variáveis ambientais, rainhas selecionadas e sistemas coletores na produção de própolis por abelhas africanizadas Apis mellifera (Hymenoptera, Apoidea). 2005. 78f. Tese de Doutorado, UNESP, Rio Claro, SP.

LOPEZ, A. M. Q. "Normas de produção da Própolis Vermelha de Alagoas", Mimeo, Documento enviado ao INPI para solicitação da Indicação Geográfica, modalidade Denominação de Origem - Mista, Maceió, 2011.

MANIA, L. F.; ASSIS, M. A. Processo de informatização do Herbário Rioclarense (HRCB) da Universidade Estadual Paulista (UNESP), Câmpus de Rio Claro, SP, e sua inclusão num sistema de rede. Revista Ciência em Extensão, v.4, n.1, p.8, 2008.

MARTINS, J. C. V.; OLIVEIRA, A. M.; MARACAJÁ, P. B. Apicultura e Inclusão Social em Assentamentos de Reforma agrária no município de APODI-RN. In: Sociedade Brasileira de Economia e Sociologia Rural. 2006, Fortaleza. Anais... Fortaleza: SOBER, 2006.

MARTINS-DA-SILVA, R. C. V.; SECCO, R.; FERREIRA, G. C.; VENTURIERI, G. C. Informatização dos herbários MG (Museu Paraense Emílio Goeldi) e IAN (EMBRAPA Amazônia Oriental). In: Simpósio Silvicultura na Amazônia Oriental: Contribuições do projeto EMBRAPA/DFID, Belém, PA. p.41-45. 1999.

MATA, V. P. Ocorrência natural e aspectos de interesse agronômico de Dalbergia ecastaphyllum (L.) Taubert (Fabaceae) no estado da Bahia: base para a produção da própolis vermelha. 2014. Dissertação (Mestrado) Universidade Federal do Recôncavo da Bahia, 2014.

MATA, V. P.; COSTA, M. A. P. C.; MORAIS, D. V.; CARVALHO, C. A. L. Germinação de sementes de Dalbergia ecastaphyllum (L.) Taubert sob diferentes temperaturas. Enciclopédia biosfera, Centro Científico Conhecer, v.10, n.18, p.1832, 2014.

MENDONÇA-MELO, L.; MOTA, E.; LOPEZ, B.; SAWAYA, A.; FREITAS, L.; JAIN, S.; ARAÚJO, E. Chemical and genetic similarity between Dalbergia ecastaphyllum and red propolis from the Northeastern Brazil. Journal of Apicultural Research, 56(1), 32-39. 2017.

MIÑO, G. P.; BALSLEV, H.; VALENCIA, R. Useful lianas of the Siona-Secoya indians from Amazonian Ecuador. Economic botany. v.49, n.3, p.269-275, 1995.

PEREIRA, D. S.; ABRANTES, M. R.; COELHO, W. A. C.; FREITAS, M. O.; FREITAS, C. I. A.; SILVA, J. B. A.. Potencial antibiótico da própolis apícola Potiguar em bactérias de importância veterinária. Revista Verde de Agroecologia e Desenvolvimento Sustentável, 11(3), 151158. (2016).

POPOVICI, A. A.; MĂRGHITAŞ, L. A.; DEZMIREAN, D. S.; ILEA, M. Advantages of the Product Diversification Strategy in Beekeeping Farms. Bulletin UASVM Animal Science and Biotechnologies 71(2). 2014.

POPOVICI A; L MĂRGHITAŞ. Entrepreneurship in the beekeeping sector. Edit. Academic Pres. Cluj-Napoca. 132133. 2013.

QGIS - Geographic Information System - (version 2.18.0). Disponível em: <http://www.qgis.org/es/site/>. Acesso em 24. mai. 2017.

RIZZINI, C. T. Árvores e madeiras úteis do Brasil: Manual de dendrologia brasileira. São Paulo: USP. 1990. 312p.

SAMBANDAN, K.; CHOWDHERY, H. J. Digital Herbarium Databases. Indian Journal of Forestry. Vol 27(3): 261-272. 2004.

SAMPAIO, I. M. FEMAP, Federação Mineira de Apicultura: rentabilidade, boas condições climáticas e qualidade do produto são alguns fatores que explicam a liderança do estado no $\quad$ 2012. Disponível em: <http://www.leccomunica.com.br/novosite/ node/>. Acesso em 10 mar. 2017.

SILVA, B. B.; ROSALEN, P. L.; CURY, J. A.; IKEGAKI, M.; SOUZA, V. C.; ESTEVES, A.; ALENCAR, S. M. Chemical Composition and Botanical Origin of Red Propolis, a New Type of Brazilian Propolis. Evidence-Based Complementary and Alternative Medicine. v.5, n.3, p.313316. 2008.

SILVA, G. F. da; VENTURIERI, G. C.; SILVA, E. S. A. Meliponicultura como alternativa de desenvolvimento sustentável: gestão financeira em estabelecimentos familiares no município de Igarapé-Açu, PA. In: Congresso Brasileiro de Apicultura, 16.; Congresso Brasileiro de Meliponicultura, 2., 2006, Aracaju. Anais ... Aracaju, 2006.

SOUZA, D. C. Importância Socioeconômica, In: SOUZA, D.C. (Org.) Apicultura: Manual do Agente de Desenvolvimento Rural, Brasília: SEBRAE, 2007. CD-ROM.

TORETI, V.C.; SATO, H.H.; PASTORE, G.M.; PARK, Y.K. Recent progress of propolis for its biological and chemical compositions and its botanical origin. Evidence-Based Complementary and Alternative Medicine, 2013.

TRUSHEVA, B.; POPOVA, M.; KOENDHORI, E. B.; TSVETKOVA, I.,; NAYDENSKI, C.; BANKOVA, V.. Indonesian propolis: chemical composition, biological activity and botanical origin. Natural Product Research, 25(6), 606-613. 2011. 